\title{
Pensamento crítico e criativo em Matemática em diretrizes curriculares nacionais
}

\author{
Mateus Gianni Fonseca ${ }^{1}$ \\ Cleyton Hércules Gontijo ${ }^{2}$
}

\begin{abstract}
RESUMO
O rápido progresso científico e tecnológico tem nutrido o estabelecimento de diferentes e inéditas demandas, enquanto o pensamento crítico e criativo vem sendo apontado em diversos trabalhos como importante para a resolução de problemas não triviais - embora haja fragilidade no que se refere à sua conceituação, mesmo em documentos oficiais. Trata-se este artigo de discussão teórica acerca do pensamento crítico e criativo, em particular no campo da matemática, a partir de uma pesquisa documental (Parâmetros Curriculares Nacionais, Base Nacional Comum Curricular e em bases de dados de produção científica). Como desdobramento da pesquisa, um conceito é proposto, juntamente com exemplos que ilustram como estimular o pensamento crítico e criativo em matemática em sala de aula. Espera-se que o mesmo seja útil para fundamentar políticas públicas educacionais, incluindo a construção de currículos escolares, e, por conseguinte, as práticas pedagógicas no campo da matemática em diferentes níveis e modalidades de ensino.
\end{abstract}

PALAVRAS-CHAVE: Educação matemática. Pensamento crítico e criativo. Pensamento crítico e criativo em matemática. Criatividade em matemática. Resolução de problemas.

Critical and creative thinking in mathematics in national curriculum guidelines

\footnotetext{
${ }^{1}$ Doutor em Educação (Educação Matemática). Instituto Federal de Educação, Ciência e Tecnologia de Brasília - IFB, Brasília, DF, Brasil. https://orcid.org/0000-0002-3373-2721.mateus.fonseca@ifb.edu.br.

2 Doutor em Psicologia. Departamento de Matemática, Universidade de Brasília, Brasília, DF, Brasil. https://orcid.org/0000-0001-6730-8243.cleyton@mat.unb.br.
} 


\begin{abstract}
Rapid scientific and technological progress has nourished the establishment of different and unprecedented demands, while critical and creative thinking has been pointed out in several works as important for solving nontrivial problems - although there is fragility regarding their conceptualization, even in official documents. This article is a theoretical discussion about critical and creative thinking, particularly in the field of mathematics, based on a documentary research (National Curriculum Parameters, Common National Curriculum Base and scientific production databases). As a result of the research, a concept is proposed, along with examples that illustrate how to stimulate critical and creative thinking in mathematics in the classroom. It is hoped that it will be useful to underpin public educational policies, including the construction of school curricula, and therefore pedagogical practices in the field of mathematics at different levels and modalities of education.
\end{abstract}

KEYWORDS: Mathematics education. Critical and creative thinking. Critical and creative thinking in mathematics. Mathematical Creativity. Problem solving.

\title{
Pensamiento crítico y creativo en matemáticas en pautas curriculares nacionales
}

\section{RESUMEN}

El rápido progreso científico y tecnológico ha suplido el establecimiento de demandas diferentes e inéditas, mientras que el pensamiento crítico y creativo se ha señalado en varios trabajos como importante para resolver problemas no triviales, aunque haya fragilidad sobre su conceptualización, incluso en documentos oficiales. Este artículo es una discusión teórica sobre el pensamiento crítico y creativo, particularmente en el campo de las matemáticas, basado en una investigación documental (Parámetros Curriculares Nacionales, Base Curricular Nacional Común y bases de datos de producción científica). Como resultado de la investigación, se propone um concepto, juntamente con ejemplos que ilustran cómo estimular el pensamiento crítico y creativo en matemáticas en aula. Se espera que sea útil para fundamentar políticas públicas educacionales, incluida la construcción de currículos escolares y, por lo tanto, las prácticas pedagógicas en el campo de las matemáticas en diferentes niveles y 
modalidades de enseñanza.

PALABRAS CLAVE: Educación matemática. Pensamiento crítico y creativo. Pensamiento crítico y creativo en matemáticas. Creatividad en matemáticas. Resolución de problemas.

$$
* * *
$$

\section{Introdução}

Por qual motivo estudamos tanto ao longo de nossas vidas, ou melhor, para que serve a Educação? Haveria uma resposta suficientemente completa que poderia esgotar esse questionamento? Provavelmente não, inclusive pelo fato de que essa resposta seria alterada se a pergunta fosse aplicada em diferentes momentos e contextos de nossa história. Todavia, tomando a legislação brasileira como referência, em especial a Lei de Diretrizes e Bases da Educação Nacional - LDB (BRASIL, 1996), encontramos que "a educação (...) tem por finalidade, o pleno desenvolvimento do educando, seu preparo para o exercício da cidadania e sua qualificação para o trabalho", o que permite inferir que estudamos como forma de nos aprimorarmos (a) cognitivamente, emocionalmente, socialmente, culturalmente etc.; (b) politicamente, de modo a exercermos nossa cidadania; e, (c) profissionalmente, tendo em vista qualificarmos nossa capacidade produtiva para o mundo do trabalho.

Ao olharmos para o passado, seja por meio dos registros históricos ou pelos relatos das memórias pessoais dos adultos de hoje, certamente concluiremos que as formas de viver a algumas décadas atrás eram muito diferentes das que encontramos no atual momento. Na década de 1960, desenhos animados como "The Jetsons" anunciavam um futuro inimaginável para boa parte da população, no qual vídeo chamadas e esteiras rolantes eram produtos comuns no contexto do desenho. Hoje, esses mesmos produtos podem ser considerados como triviais nos mais variados espaços sociais. Todavia, as 
visões futurísticas no passado permitiram avanços, como o que ocorreu nos primeiros anos da década de 1990, quando surgiram os smartphones, combinando telefonia celular a uma série de tecnologias de computação e mostrando possibilidades ainda não imaginadas pelos "The Jetsons". Tantas inovações científicas e tecnológicas certamente alteraram o modo de vida das pessoas em diferentes esferas, como no âmbito pessoal e profissional.

A dinâmica da vida moderna, seja referente ao desenvolvimento científico e tecnológico ou na realização de tarefas corriqueiras do cotidiano, tem exigido que as pessoas pensem criativamente para encontrar diferentes caminhos que melhor conduzam à solução de seus problemas e, ao mesmo tempo, pensem criticamente sobre esses caminhos para poderem tomar decisões apropriadas no curso da resolução dos problemas. Não é diferente no âmbito do mundo do trabalho, onde a tomada de decisão, a abertura à novas ideias e a necessidade de inovação a todo instante demandam o pensamento crítico e criativo. Vale mencionar que a LDB prescreve como uma finalidade do Ensino Médio, última etapa da educação básica brasileira, "o aprimoramento do educando como pessoa humana, incluindo a formação ética e o desenvolvimento da autonomia intelectual e do pensamento crítico" (BRASIL, 1996).

No cenário internacional são encontradas iniciativas como a Partnership for 21st Century Learning - P21 (P21, 2016), que em defesa de uma educação sintonizada com as necessidades do atual momento, propõe que os sistemas educativos privilegiem no processo formativo dos estudantes o desenvolvimento de 6 C's: colaboration, communication, conectivity, culture, creativity e critical thinking. Sendo estes dois últimos o objeto aqui em discussão.

O pensamento crítico e criativo deve ser estimulado nas diferentes áreas do conhecimento. Entretanto, para este artigo, optou-se por focar apenas no campo da matemática, valendo destacar que a matemática é instrumento indispensável em diferentes áreas, em especial do desenvolvimento científico e tecnológico (KANHAI; SINGH, 2014), afinal, o 
progresso tecnológico e as invenções e o desenvolvimento da matemática estão interligados: o desenvolvimento da matemática facilita o progresso tecnológico e, por sua vez, o avanço da ciência e da tecnologia impulsionam o desenvolvimento da matemática.

Embora haja um movimento de reconhecimento da necessidade de se estimular o pensamento crítico e criativo em matemática, não há consenso sobre o que o caracteriza esse tipo de pensamento. Em muitos discursos, parece que os argumentos ficam circunscritos no universo do senso comum em função da polissemia que esses termos possuem, carecendo de um debate de natureza científica. Ressalta-se, entretanto, que no cenário internacional há uma vasta literatura sobre o assunto, enquanto no cenário brasileiro são recentes as iniciativas de pesquisadores apresentando proposição de conceitos e formas de operacionaliza-los no âmbito da matemática escolar (FONSECA, GONTIJO, ZANETTI, 2018; FONSECA, GONTIJO, ZANETTI, CARVALHO, 2019; FONSECA, 2015; GONTIJO, 2007a, 2007b, 2015; GONTIJO, SILVA, CARVALHO, 2012; GONTIJO, FONSECA, ZANETTI, 2019; SOUZA, GONTIJO, FONSECA, 2019).

Dessa forma, o objetivo deste artigo é apresentar um levantamento de dados acerca de como é tratado o termo "pensamento crítico e criativo em matemática" em documentos oficiais brasileiros e em bases de dados de produção científica, para propor uma conceituação desses termos. Ademais, ousamos exemplificar por meio de duas atividades como o pensamento crítico e criativo pode ser estimulado em sala de aula. Acreditamos que uma definição proposta, juntamente com exemplos, poderá contribuir para fundamentar políticas públicas educacionais, incluindo a construção de currículos escolares e, por conseguinte, para as práticas pedagógicas no campo da matemática em diferentes níveis e modalidades de ensino.

\section{Pesquisas em pensamento crítico e criativo na Educação Matemática}

O Critical Thinking Consortium - $\mathrm{TC}^{2}$ é uma iniciativa canadense que 
possui por missão tentar engajar organizações e professores no apoio e na defesa da "infusão do pensamento crítico, criativo e colaborativo como um objetivo educacional e como um método de ensino aprendizagem”. Para eles quando os estudantes pensam criticamente em matemática:

[...] eles tomam decisões e fazem julgamentos sobre suas ações e ideias. Em outras palavras, eles consideram critérios e bases para uma decisão ponderada e não apenas tentam adivinhar ou aplicar uma regra sem avaliar sua relevância ${ }^{3}$ (s.d)

É possível inferir que o aprimoramento do pensamento crítico e criativo em matemática pode desenvolver também o conhecimento matemático do estudante, afinal, em situações de resolução de problemas, o exercício do pensar e do julgar acerca dos melhores caminhos para encontrar a solução mais apropriada se dá num cenário de produção genuinamente matemática e não apenas num contexto de aplicação/replicação de algoritmos e procedimentos técnicos. Nesse sentido, o estudante atua como um matemático, guardadas as devidas proporções. (AIKEN, 1973; GONTIJO 2007b, LEIKIN, PANTAZI, 2013, FONSECA, 2015).

Facione (2011, apud, FIRDAUS, KAILANI, BAKAR, BAKRY, 2015) diz que o conceito mais básico para pensamento crítico se refere a "habilidade de interpretação, análise, avaliação, inferência, explanação e autorregulação". Fridaus e colaboradores (2015) defendem que o pensamento crítico em matemática é importante, tendo em vista que essa capacidade de pensamento pode aprimorar a qualidade da aprendizagem matemática e, portanto, deve ser estimulado quando são trabalhados os conteúdos de matemática na escola, pois, segundo os autores, "os estudantes não devem apenas entender o conteúdo de matemática, mas também o processo do pensamento matemático" (p. 227).

Sobre o pensamento criativo em matemática, por sua vez, diferentes

\footnotetext{
${ }^{3}$ Disponível em: < https://tc2.ca >. Acesso em: 13 out. 2019.
} 
autores destacam a necessidade de se possuir conhecimento de domínio, isto é, de matemática, e de flexibilidade de pensamento para apresentar soluções inovadoras para os problemas (HAYLOCK, 1997). Numa tentativa de sumarizar pontos comuns de diferentes conceituações de criatividade em matemática e apresentar um conceito possível de ser operacionalizado no espaço escolar, Gontijo (2007b, p. 38), definiu criatividade em matemática como:

A capacidade de apresentar inúmeras possibilidades de solução apropriadas para uma situação-problema, de modo que estas focalizem aspectos distintos do problema e/ou formas diferenciadas de solucioná-lo, especialmente formas incomuns (originalidade), tanto em situações que requeiram a resolução e elaboração de problemas como em situações que solicitem a classificação ou organização de objetos e/ou elementos matemáticos em função de suas propriedades e atributos, seja textualmente, numericamente, graficamente ou na forma de uma sequência de ações.

Nessa definição e em outras no campo da criatividade, valoriza-se três traços latentes da criatividade, a saber: (a) fluência; (b) flexibilidade; e, (c) originalidade. Fonseca (2015, p. 46) explicita cada traço, pontuando que:

À fluência, cabe definir, é a capacidade em se gerar múltiplas ideias, múltiplas soluções, para a resolução do problema; flexibilidade se relaciona a geração de soluções que podem ser observadas sob categorias diversas das quais já foram propostas; enquanto, por fim, originalidade está ligada à novidade, a não convencionalidade da solução proposta dentre as demais.

Ao considerar as características do pensamento criativo (fluência, flexibilidade e originalidade de pensamento), podemos estabelecer uma conexão com elementos caracterizadores do pensamento crítico. Enquanto 
alguns pesquisadores mencionam apenas o pensamento crítico e outros apenas o pensamento criativo, argumentamos que essas duas formas de pensar possuem conexões, pois, pensar criativamente leva à produção de muitas ideias, que sob o julgo do pensamento crítico, favorece a tomada de decisão, isto é, a escolha dentre todas as ideias, as melhores ou as mais apropriadas para uma determinada situação.

Essa forma de considerar pensamento crítico e criativo encontra respaldo em outros trabalhos, por exemplo, em Lipman (2003), que considera que o pensamento é intrinsecamente crítico e criativo, visto que existem fases nas quais se requer criatividade para gerar ideias novas e diferentes para a resolução de problemas. Fases essas, seguidas de etapas que demandam avaliação e tomadas de decisão no curso das ações, exigindo, assim, pensamento crítico. Dessa forma, os processos criativos interagem com os de pensamento crítico em diferentes fases do processo de resolução de problemas.

Attard (2017) salienta a necessidade de ensinar matemática a partir do pensamento crítico e criativo, dizendo, assertivamente, que "de fato, é obrigatório". Para ela, "pensamento crítico e criativo é algo que nós não podemos ignorar se quisermos que nossos estudantes estejam preparados para a força de trabalho e para o mundo que muda constantemente”. Esperase, portanto, que com o desenvolvimento de habilidades relacionadas ao pensamento crítico e criativo os estudantes tenham condições de mobilizar seus conhecimentos em prol de solucionar diferentes problemas - o que o favorece na vida cotidiana como também no mundo do trabalho.

\section{Método}

Partindo-se do objetivo de apresentar uma conceituação acerca do pensamento crítico e criativo em matemática, optou-se por uma pesquisa documental (GIL, 2008) de cunho exploratório, visto que analisamos documentos norteadores da educação brasileira. Foram selecionados dois textos oficiais: Parâmetros Curriculares Nacionais (Ensino Médio), Parte III, 
que trata da área das Ciências da Natureza, Matemática e suas Tecnologias (BRASIL, 2000) e a Base Nacional Comum Curricular - Ensino Médio (BRASIL, 2018). Buscou-se nesses documentos a presença dos radicais "criativ" e "critic", por meio de ferramenta de busca do software Adobe Reader, que foi utilizado na leitura da versão eletrônica dos textos. Foram elaboradas sínteses acerca das ideias principais envolvidas em cada uma das citações nas quais esses radicais apareceram, de modo a compreender os significados atribuídos às palavras criatividade e criticidade.

Adicionalmente, procedeu-se uma busca no Portal de Periódico Capes/MEC e na base de dados Scielo para verificar como esse tema tem sido abordado na produção acadêmica, utilizando os termos "pensamento crítico e criativo" e "pensamento crítico e criativo em matemática".

\section{Análise e resultados}

No que se refere à mineração dos radicais realizada no texto dos PCN do Ensino Médio, foram encontradas 3 ocorrências para o radical "criativ" e 8, para "critic". Ressalte-se que 3 das ocorrências do radical "critic" referiam especificamente ao contexto da química e da física, razão pela qual não foram tratados neste artigo. E, por esse motivo, foram consideradas 5 ocorrências no que se refere ao radical mencionado. O quadro-resumo (ver Quadro 1) apresenta cada contexto na qual foram extraídos os radicais (marcados de negrito), bem como a transcrição textual do trecho em que cada um aparece no documento:

QUADRO 1: Quadro-resumo de ocorrências do prefixo “criativ" - PCN

\begin{tabular}{|c|c|c|}
\hline Página & Contexto & Trecho textual \\
\hline \multirow{7}{7}{} & $\begin{array}{c}\text { O sentido do } \\
\text { aprendizado na } \\
\text { área (de } \\
\text { ciências e } \\
\text { matemática) }\end{array}$ & $\begin{array}{c}\text { "Deve propiciar a construção de compreensão dinâmica da nossa vivência } \\
\text { material, de convívio harmônico com o mundo da informação, de } \\
\text { entendimento histórico da vida social e produtiva, de percepção evolutiva da } \\
\text { vida, do planeta e do cosmos, enfim, um aprendizado com caráter prático e } \\
\text { crítico e uma participação no romance da cultura científica, ingrediente } \\
\text { essencial da aventura humana" }\end{array}$ \\
\hline
\end{tabular}




\begin{tabular}{|c|c|c|}
\hline 12 & $\begin{array}{l}\text { Competências } \\
\text { e habilidades } \\
\text { (Investigação e } \\
\text { compreensão) }\end{array}$ & "Interpretar e criticar resultados a partir de experimentos e demonstrações" \\
\hline 40 & $\begin{array}{l}\text { Conhecimentos } \\
\text { de matemática }\end{array}$ & $\begin{array}{l}\text { "Em seu papel formativo, a Matemática contribui para o desenvolvimento de } \\
\text { processos de pensamento e a aquisição de atitudes, cuja utilidade e alcance } \\
\text { transcendem o âmbito da própria Matemática, podendo formar no aluno a } \\
\text { capacidade de resolver problemas genuínos, gerando hábitos de } \\
\text { investigação, proporcionando confiança e desprendimento para analisar e } \\
\text { enfrentar situações novas, propiciando a formação de uma visão ampla e } \\
\text { científica da realidade, a percepção da beleza e da harmonia, o } \\
\text { desenvolvimento da criatividade e de outras capacidades pessoais" }\end{array}$ \\
\hline 42 & $\begin{array}{l}\text { Conhecimentos } \\
\text { de matemática }\end{array}$ & $\begin{array}{c}\text { "As finalidades do ensino de Matemática no nível médio indicam como } \\
\text { objetivos levar o aluno a:” (...) } \\
\text { "analisar e valorizar informações provenientes de diferentes fontes, } \\
\text { utilizando ferramentas matemáticas para formar uma opinião própria que lhe } \\
\text { permita expressar-se criticamente sobre problemas da Matemática, das } \\
\text { outras áreas do conhecimento e da atualidade" }\end{array}$ \\
\hline 42 & $\begin{array}{l}\text { Conhecimentos } \\
\text { de matemática }\end{array}$ & $\begin{array}{l}\text { "As finalidades do ensino de Matemática no nível médio indicam como } \\
\text { objetivos levar o aluno a:" (...) } \\
\text { “desenvolver as capacidades de raciocínio e resolução de problemas, de } \\
\text { comunicação, bem como o espírito crítico e criativo" }\end{array}$ \\
\hline 46 & $\begin{array}{l}\text { Competências } \\
\text { e habilidades a } \\
\quad \text { serem } \\
\text { desenvolvidas } \\
\text { em matemática } \\
\text { (Investigação e } \\
\text { compreensão) }\end{array}$ & "Interpretar e criticar resultados numa situação concreta" \\
\hline 53 & $\begin{array}{l}\text { Rumos e } \\
\text { desafios }\end{array}$ & $\begin{array}{c}\text { "A aula expositiva é só um dos muitos meios [de se ensinar matemática] e } \\
\text { deve ser o momento do diálogo, do exercício da criatividade e do trabalho } \\
\text { coletivo de elaboração do conhecimento" }\end{array}$ \\
\hline
\end{tabular}

Fonte: Elaborado pelos pesquisadores

O quadro-resumo 1 mostra que os termos foram aplicados em diferentes contextos, tendo sido associados a diversas situações, incluindo os conhecimentos matemáticos a serem desenvolvidos ao longo da escolarização e desafios para o ensino dessa disciplina. No entanto, embora seja possível depreender algum sentido sobre esses termos, o documento não os conceitua explicitamente. Isso pode se configurar como um obstáculo para a escolha de estratégias didáticas pelo professor para promover o "espírito crítico e criativo" em sua prática pedagógica, pois, não há subsídios no documento que ilustrem como estimular essa tipo de pensamento. 
Em seguida, procedeu-se o mesmo caminho na análise da BNCC Ensino Médio. Ressalta-se que esse documento, publicado em 2018, é mais recente do que os PCN analisados, cuja data de publicação é de 2000. Com a inscrição do prefixo 'criativ', o software utilizado na leitura da versão eletrônica retornou 27 recorrências; enquanto para o prefixo "critic" foram apresentadas 104. A alta recorrência desse último prefixo está relacionada à variedade de sentidos que ele pode assumir, sem necessariamente estar ligado ao que aqui discutimos acerca do pensamento crítico. Alguns exemplos de situações distintas de pensamento crítico: análise crítica, forma crítica, consciência crítica, autocrítica, crítica aos diferentes usos das linguagens etc. A análise detalhada do contexto no qual essas expressões apareceram revelou não se tratar da ideia de "pensamento crítico" em si.

Do montante encontrado, apenas 6 ocorrências do termo "criativ" foram selecionadas, uma vez estarem ligadas às competências gerais ou competências específicas da matemática, enquanto as demais ocorrências se referem a outros campos do conhecimento e/ou competências específicas. De igual modo, apenas 10 ocorrências oriundas do radical "critic" foram selecionadas para análise. Os contextos em que foram apresentados, bem como os trechos em que foram citados constam no Quadro 2:

QUADRO 2: Quadro-resumo de ocorrências do prefixo "criativ" - BNCC

\begin{tabular}{|c|c|c|c|}
\hline Página & Contexto & Trecho textual \\
\hline 9 & $\begin{array}{c}\text { Competências } \\
\text { gerais da } \\
\text { educação } \\
\text { básica }\end{array}$ & $\begin{array}{c}\text { "Exercitar a curiosidade intelectual e recorrer à abordagem própria das } \\
\text { ciências, incluindo a investigação, a reflexão, a análise crítica, a } \\
\text { imaginação e a criatividade, para investigar causas, elaborar e testar } \\
\text { hipóteses, formular e resolver problemas e criar soluções (inclusive } \\
\text { tecnológicas) com base nos conhecimentos das diferentes áreas" } \\
\text { "Compreender, utilizar e criar tecnologias digitais de informação e } \\
\text { comicação de forma crítica, significativa, reflexiva e ética nas diversas } \\
\text { práticas sociais (incluindo escolares) para se comunicar, acessar e } \\
\text { disseminar informações, produzir conhecimentos, resolver problemas e } \\
\text { exercer protagonismo e autoria na vida pessoal e coletiva" }\end{array}$ \\
& $\begin{array}{c}\text { "Valorizar a diversidade de saberes e vivências culturais e apropriar-se de } \\
\text { conhecimentos e experiências que lhe possibilitem entender as relações } \\
\text { próprias do mundo do trabalho e fazer escolhas alinhadas ao exercício da } \\
\text { cidadania e ao seu projeto de vida, com liberdade, autonomia, consciência }\end{array}$ \\
\hline
\end{tabular}




\begin{tabular}{|c|c|c|}
\hline & & crítica e responsabilidade" \\
\hline 14 & $\begin{array}{l}\text { Demandas } \\
\text { para os dias } \\
\text { atuais }\end{array}$ & $\begin{array}{l}\text { "No novo cenário mundial, reconhecer-se em seu contexto histórico e } \\
\text { cultural, comunicar-se, ser criativo, analítico-crítico, participativo, aberto } \\
\text { ao novo, colaborativo, resiliente, produtivo e responsável requer muito mais } \\
\text { do que o acúmulo de informações" } \\
\text { "Trata-se, portanto, de adotar uma noção ampliada e plural de juventude, } \\
\text { entendida como diversa, dinâmica e participante ativa do processo de } \\
\text { formação que deve garantir sua inserção autônoma e crítica no mundo. As } \\
\text { juventudes estão em constante diálogo com outras categorias sociais, } \\
\text { encontram-se imersas nas questões de seu tempo e têm importante função } \\
\text { na definição dos rumos da sociedade." } \\
\text { "Nesse sentido, cabe às escolas de Ensino Médio contribuir para a formação } \\
\text { de jovens críticos e autônomos, entendendo a crítica como a compreensão } \\
\text { informada dos fenômenos naturais e culturais, e a autonomia como a } \\
\text { capacidade de tomar decisões fundamentadas e responsáveis. Para acolher } \\
\text { as juventudes, as escolas devem proporcionar experiências e processos } \\
\text { intencionais que lhes garantam as aprendizagens necessárias e promover } \\
\text { situações nas quais o respeito à pessoa humana e aos seus direitos sejam } \\
\text { permanentes" }\end{array}$ \\
\hline 464 & $\begin{array}{c}\text { Ensino médio } \\
\text { no contexto } \\
\text { da Educação } \\
\text { Básica }\end{array}$ & $\begin{array}{l}\text { Finalidades do ensino médio, citando LDB: "III - o aprimoramento do } \\
\text { educando como pessoa humana, incluindo a formação ética e o } \\
\text { desenvolvimento } \\
\text { da autonomia intelectual e do pensamento crítico" } \\
\text { "promover o desenvolvimento de competências que possibilitem aos } \\
\text { estudantes inserir-se de forma ativa, crítica, criativa e responsável em um } \\
\text { mundo do trabalho cada vez mais complexo e imprevisível (...)" }\end{array}$ \\
\hline 465 & $\begin{array}{l}\text { Preparação } \\
\text { para o } \\
\text { mercado de } \\
\text { trabalho }\end{array}$ & $\begin{array}{l}\text { "promover o desenvolvimento de competências que possibilitem aos } \\
\text { estudantes inserir-se de forma ativa, crítica, criativa e responsável em um } \\
\text { mundo do trabalho cada vez mais complexo e imprevisível (...)" }\end{array}$ \\
\hline 518 & Matemática & $\begin{array}{c}\text { "Matemática e suas Tecnologias diante da responsabilidade de aproveitar } \\
\text { todo o potencial já constituído por esses estudantes, para promover ações } \\
\text { que estimulem e provoquem seus processos de reflexão e de abstração, que } \\
\text { deem sustentação a modos de pensar criativos, analíticos, indutivos, } \\
\text { dedutivos e sistêmicos e que favoreçam a tomada de decisões orientadas } \\
\text { pela ética e o bem comum" }\end{array}$ \\
\hline 520 & Matemática & $\begin{array}{c}\text { “(..) indagações do tipo “e se fosse?”, que mobilizam processos de } \\
\text { abstrações, representações e generalizações, essenciais para a criatividade } \\
\text { em Matemática” }\end{array}$ \\
\hline 522 & Matemática & $\begin{array}{c}\text { "O letramento deve também assegurar que todos os estudantes reconheçam } \\
\text { que os conhecimentos matemáticos são fundamentais para compreender e } \\
\text { atuar no mundo e para que também percebam o caráter de jogo intelectual } \\
\text { da Matemática, como aspecto que favorece o desenvolvimento do raciocínio } \\
\text { lógico e crítico, estimula a investigação e que pode também ser prazeroso } \\
\text { (fruição)." }\end{array}$ \\
\hline
\end{tabular}




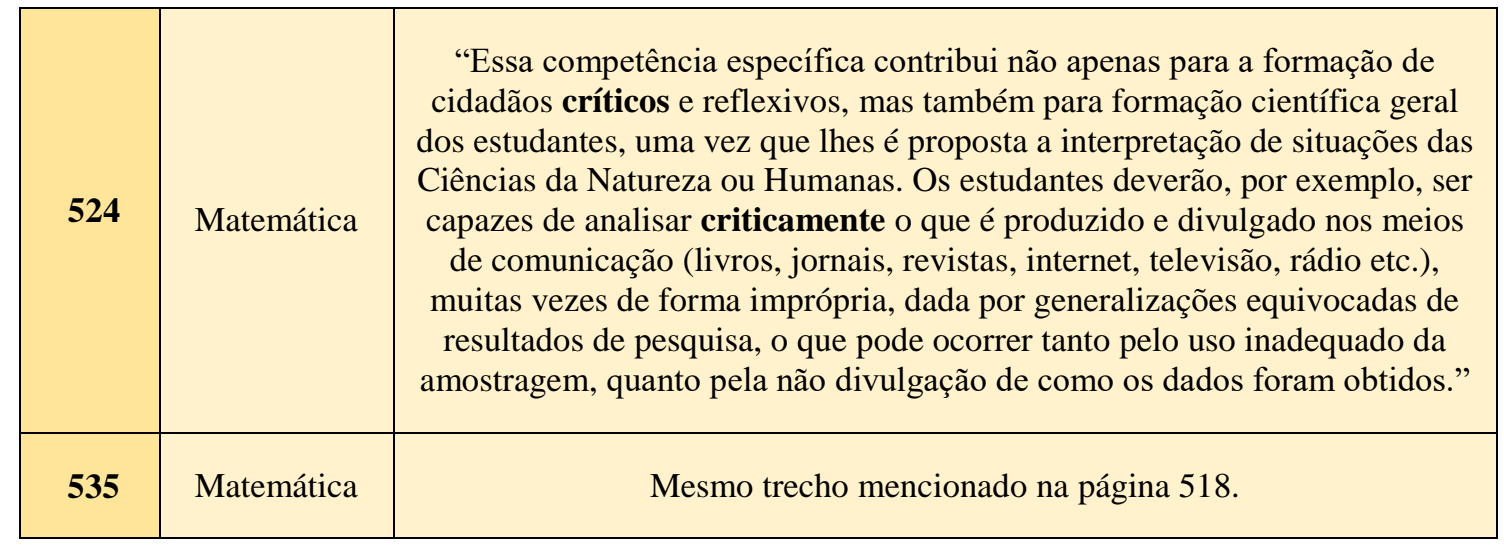

Fonte: Elaborado pelos autores

Adicionalmente, para verificar como esse tema tem sido abordado no Brasil, realizamos uma consulta utilizando os termos "pensamento crítico e criativo" no campo "assunto" em duas bases de dados: Portal de Periódico Capes/MEC e Scielo. Foram encontradas 14 produções, sendo 11 no Portal de Periódico Capes/MEC e 3 na base de dados Scielo. Nesse conjunto, no entanto, identificamos duplicidade em duas produções, visto que foram mencionadas em ambas as consultas, restando, portanto, 12 produções diferentes. A análise dos resumos dessas produções apontou tratarem-se de investigações na área de comunicação, teatro e pedagogia, ou seja, não tendo por foco a aplicação do pensamento crítico e criativo no campo específico da matemática.

A partir da consulta nessas mesmas bases de dados, utilizando os termos "pensamento crítico e criativo" combinado com "matemática", foram encontradas 4 produções científicas, sendo 3 no Portal de Periódicos Capes/MEC e 1 na base de dados Scielo. Vale destacar que essas já haviam sido mencionadas na busca anterior quando foram utilizados apenas os termos "pensamento crítico e criativo". O quadro abaixo apresenta os títulos e os objetivos de cada uma dessas produções:

QUADRO 3: Busca em bases de dados: "pensamento crítico e criativo" AND "matemática"

\begin{tabular}{|c|c|c|}
\hline $\begin{array}{c}\text { Base de } \\
\text { dados }\end{array}$ & $\begin{array}{c}\text { Títulos } \\
\text { encontrados }\end{array}$ & Objetivos \\
\hline $\begin{array}{c}\text { Portal de } \\
\text { periódicos }\end{array}$ & Análise das & $\begin{array}{c}\text { "analisar a qualidade de uma base de dados de WebQuests em } \\
\text { língua portuguesa disponibilizadas online em dois níveis: }\end{array}$ \\
\hline
\end{tabular}




\begin{tabular}{|c|c|c|}
\hline \multirow[t]{3}{*}{ Capes/MEC } & $\begin{array}{c}\text { componentes e a } \\
\text { usabilidade das } \\
\text { webquests em } \\
\text { língua portuguesa } \\
\text { disponíveis na web: } \\
\text { um estudo } \\
\text { exploratório }\end{array}$ & conteúdo e usabilidade" \\
\hline & $\begin{array}{c}\text { Uma fundamentação } \\
\text { teórica para as } \\
\text { coreografias } \\
\text { didáticas no } \\
\text { ambiente virtual de } \\
\text { aprendizagem }\end{array}$ & $\begin{array}{l}\text { "discutir sobre a fundamentação teórica para a utilização da } \\
\text { plataforma Moodle no contexto da Coreografia Didática e do } \\
\text { design instrucional considerando os novos desafios midiáticos e } \\
\text { colaborativos enfrentados pelos professores em sua prática } \\
\text { pedagógica no ambiente virtual de aprendizagem" }\end{array}$ \\
\hline & $\begin{array}{l}\text { O professor e a } \\
\text { formação docente: a } \\
\text { criatividade e as } \\
\text { crenças educativas } \\
\text { onde estão? }\end{array}$ & $\begin{array}{l}\text { "refletir sobre a criatividade e as crenças como elemento da } \\
\text { formação docente e da atuação profissional do professor" }\end{array}$ \\
\hline Scielo & $\begin{array}{c}\text { Estrategias de } \\
\text { aprendizaje, } \\
\text { comprensión lectora } \\
\text { y rendimento } \\
\text { académico em } \\
\text { Educación } \\
\text { Secundaria }\end{array}$ & $\begin{array}{c}\text { "analisar as estratégias de aprendizagem, o controle da } \\
\text { compreensão leitora e o rendimento acadêmico em língua } \\
\text { castelhana e matemática em uma amostra de } 118 \text { alunos de } \\
\text { Educação Secundária de Madri”" }\end{array}$ \\
\hline
\end{tabular}

Fonte: Elaborado pelos pesquisadores

A partir da leitura dos objetivos, seguida de leitura flutuante dos referidos textos, percebemos que tanto o termo "pensamento crítico e criativo" quanto "matemática" não estavam associados necessariamente a um conceito formal - isso justifica porque estes trabalhos não haviam sido selecionados quando na leitura de seus resumos na primeira pesquisa realizada junto às bases de dados.

A exceção se aplica apenas ao texto "Estrategias de aprendizaje, comprensión lectora y rendimento académico em Educación Secundaria”, de Pinto, Martínez e Jiménez-Taracido (2016), que dentre outros interesses, buscou analisar o pensamento crítico e criativo como uma estratégia de pensamento ligada à reflexão, bem como da flexibilidade mental e persistência nas tarefas a partir das informações dadas em favor de alcançar conclusões. Os pesquisadores concluíram que o pensamento crítico e criativo é uma estratégia de pensamento presente nas produções dos estudantes 
considerados bons leitores.

Não foram encontrados resultados a partir do termo "pensamento crítico e criativo em matemática" em ambas as bases de dados. Isso reforça o quanto esse objeto ainda não se encontra na mira dos pesquisadores da comunidade de educação matemática brasileira. $\mathrm{O}$ fato do termo ser comumente encontrado em diferentes políticas públicas e documentos oficiais pode gerar uma compreensão falaciosa de que o conceito já está bem definido, quando na verdade parece estarmos diante de uma verdadeira ilusão de ótica que pode não atrair pesquisadores para a investigação do tema. Há o risco, portanto, de muito se falar de pensamento crítico e criativo nos currículos de matemática dos diferentes níveis escolares sem, no entanto, haver clareza do que isso significa.

A partir dos elementos encontrados, pode-se apresentar alguns questionamentos, tais como: Qual diferença entre imaginação e criatividade? O que se espera de uma pessoa criativa? O que é um modo de pensar crítico e criativo? Como o pensamento crítico e criativo pode contribuir para a tomada de decisões? Como estimular o pensamento crítico e criativo dos estudantes? e, afinal, o que é pensamento crítico e criativo? E, mais especificamente, o que é pensamento crítico e criativo em matemática?

De fato, o documento menciona o termo criatividade diversas vezes e, faz o mesmo em menor escala em relação à "criatividade em matemática", embora não apresente qualquer definição. Igualmente ocorre também com a ideia do pensamento crítico em matemática. E mais, ainda menciona serem capacidades importantes para a inserção no mercado de trabalho sem, no entanto, avançar em como operacionalizar ações que contribuam para desenvolver tais criatividades dos estudantes. Ressalta-se a dificuldade de se depreender uma definição ainda que subjetiva destes termos a partir da leitura desses textos, visto que esse estão sempre associados a outros termos e/ou contextos que também se encontram sem definição explícita.

Em suma, dois pontos emergem a partir dos Quadros 1 e 2, relativos aos dois documentos em análise: (a) não há uma definição formal sobre o que 
é pensamento crítico e criativo, o que permite múltiplas interpretações, inclusive, noções baseadas no senso comum e até mesmo compreensões contraditórias acerca dos termos; e, (b) não há indícios, sugestões e/ou orientações acerca de como estimular tais capacidades no cotidiano escolar e, tampouco, a indicação de referências que possam subsidiar os professores para o desenvolvimento do pensamento crítico e criativo dos estudantes.

Ressalta-se que, embora os termos ligados ao pensamento crítico e criativo se fazem mais presentes no documento da BNCC, a ausência de conceito pode ser um fator dificultador para que se promova o avançar no ensino de matemática brasileiro no tocante a este ponto. Isso tanto na formação geral do estudante, no que diz respeito ao prosseguimento dos estudos, quanto no desenvolvimento de competências profissionais que lhe oportunize a inserção no mercado de trabalho.

\section{Pensamento crítico e criativo}

A partir das definições presentes na literatura para pensamento crítico e para criatividade em matemática mencionadas na seção introdutória deste artigo, ousamos propor uma definição que possa ser utilizada para fundamentar demais pesquisas, elaborar documentos norteadores e/ou políticas públicas e viabilizar a construção de instrumentos de mensuração dessas habilidades de pensamento que permita operacionalizar pesquisas na área. A apresentação formal do conceito também pode ser útil para florescer maior número de pesquisas na área e assim aprimorar o entendimento de um pensamento matemático que deve estar presente nos dias de hoje seja para o cidadão inserido no mundo do trabalho, em atividades acadêmicas ou mesmo ou para as atividades cotidianas.

Assim, entendemos por pensamento crítico e criativo em matemática como a ação coordenada de geração de múltiplas e diferentes ideias para solucionar problemas (fluência e flexibilidade de pensamento) com o processo de tomadas de decisão no curso da elaboração dessas ideias, envolvendo 
análises dos dados e avaliação de evidências de que os caminhos propostos são plausíveis e apropriados para se chegar à solução, argumentando em favor da melhor ideia para alcançar o objetivo do problema (originalidade ou adequação ao contexto). Em outras palavras, o uso do pensamento crítico e criativo se materializa por meio da adoção de múltiplas estratégias para se encontrar resposta(s) para um mesmo problema associada à capacidade de refletir sobre as estratégias criadas, analisando-as, questionando-as e interpretando-as a fim de apresentar a melhor solução possível.

Para ilustrar uma aplicação do conceito, será apresentado a seguir um exemplo de problema que requer dos estudantes o uso do pensamento crítico e criativo em matemática:

Os preços dos ingressos para entrar em um parque de diversões são: $R \$ 10,00$ para crianças e $R \$ 30,00$ para adultos. Supondo que em determinado dia a arrecadação foi de $R \$ 2000,00$, responda: Qual o número de pessoas, entre crianças e adultos, que poderiam frequentar o parque nesse dia? Quantas crianças e quantos adultos?

Uma solução possível é "200 crianças e 0 adultos", pois atende à condição exposta no problema. Todavia, é plausível acreditar que haja 200 crianças no parque de diversões e nenhum adulto? Tal questionamento serve para reforçar a importância do pensamento crítico em matemática. Não se trata apenas de realizar procedimentos matemáticos, mas também de interpretar os resultados encontrados. Nesse ponto se evidencia uma das diferenças entre se trabalhar apenas com a equação e em se trabalhar com a equação a partir de um contexto.

Outra possibilidade de resposta é contar com a presença de apenas 1 adulto junto à 197 crianças. De forma semelhante à solução apresentada anteriormente, questiona-se a razoabilidade da resposta. $\mathrm{O}$ pensamento crítico deve contribuir para que os estudantes formulem ideias, argumentando a favor de soluções que acreditam serem possíveis em 
situações reais, visto que 197 crianças e 1 adulto, do ponto de vista estritamente matemático, é uma resposta válida.

Considerando as respostas apresentadas, vale problematizar junto aos estudantes a busca por uma solução que apresente uma relação crianças/adultos mais equilibrada. Nessa problematização, poder-se-ia discutir com os estudantes a ideia de proporção de crianças por adultos a partir de suas realidades de vida familiar. Talvez, a relação de 2 ou 3 crianças para cada adulto seja um caminho. E assim, uma resposta com 80 crianças e 40 adultos pode surgir.

Vale ressaltar que esse problema se caracteriza como aberto, isto é, admite múltiplas possibilidades de solução. Problemas dessa natureza são especialmente importantes para o desenvolvimento do pensamento criativo em matemática, pois permitem a geração de muitas ideias (fluência), abordando diferentes configurações de soluções (flexibilidade) e a possibilidade de respostas incomuns (originalidade) que possam resolver o problema de forma adequada e com razoabilidade.

Apresentamos a seguir outro exemplo que serve para ilustrar a aplicação do pensamento crítico e criativo em matemática. Este ganhou notoriedade nas redes sociais, depois que um professor, na China, o apresentou para os estudantes. Tal notoriedade deve-se à relação (ou falta de) entre os dados apresentados e o comando para a execução de estratégias de solução.

Se um navio tem 26 ovelhas e dez bodes a bordo, qual é a idade do capitão do navio?

Este é um problema onde memorizar sequências de algoritmos não faz diferença, afinal, sequer existem os dados necessários para responder tal questão. A riqueza da tarefa está em identificar o que fora oferecido de informação e o objetivo do problema. E, em seguida, problematizar, raciocinar, conjecturar estratégias e/ou soluções a partir de argumentos. 
Como respostas para esse problema, circularam nas redes sociais soluções consideradas não críticas, como 36 (26 ovelhas +10 bodes) e 16 (26 ovelhas - 10 bodes), obtidas a partir da adição e da subtração dos dois números indicados, revelando que muitos estudantes julgam que resolver problemas consiste na manipulação numérica dos valores apresentados, sem analisar a plausibilidade do fato e/ou do resultado encontrado.

Por se tratar de um problema que não admite solução matemática, visto que não é possível calcular a idade do capitão a partir das cargas transportadas no navio, outras estratégias argumentativas devem ser estimuladas, inclusive a indicação da impossibilidade de solução. Entretanto, não sendo possível solução matemática, poder-se-ia estimular a apresentação de estimativas para a idade do capitão considerando variáveis não apresentadas no problema. Em uma matéria do site Ciberia ${ }^{4}$ foi publicada uma resposta de um internauta para esse problema:

O peso total de 26 ovelhas e 10 cabras é $7.700 \mathrm{~kg}$, com base no peso médio de cada animal. Na China, para conduzir um navio com mais de $5.000 \mathrm{~kg}$ de carga, é preciso ter uma licença de barco há cinco anos. A idade mínima para conseguir uma licença é 23 anos, por isso, o capitão tem, pelo menos, 28 anos.

Vale destacar que assim que esse problema ganhou notoriedade e discussão pela internet, por inicialmente se enquadrar em um item impossível, o Departamento Educacional de Shunqing se pronunciou alegando que o objetivo era examinar o pensamento crítico das crianças. Acrescentamos aos objetivos desse tipo de problema o estímulo ao pensamento criativo, pois, o processo de geração de múltiplas respostas (fluência de pensamento), combinando diferentes variáveis em cada solução (flexibilidade de pensamento) pode favorecer o surgimento de respostas inovadores em

\footnotetext{
4 Disponível em <https://ciberia.com.br/se-um-navio-tiver-26-ovelhas-e-10-cabras-bordo-quantos-anos-tem-ocapitao-do-navio-32800>. Acesso em 13 out. 2019.
} 
determinados contextos (originalidade de pensamento), que são indicadores de criatividade.

Diferentes problemas possuem potencial para estimular o pensamento crítico e criativo em matemática. A elaboração de problemas ou a transformações daqueles que são típicos de livros didáticos em formato de problemas abertos que contemplem múltiplas possibilidade de respostas podem favorecer uma nova dinâmica no espaço da sala de aula, motivando os estudantes e estimulando-os a pensar de forma crítica e criativa em suas produções.

\section{Conclusão}

Muitas das práticas pedagógicas no ensino da matemática ainda enfatizam ou priorizam a memorização de algoritmos e fórmulas para resolver problemas, que geralmente apresentam apenas um caminho para chegar à sua solução. Nas práticas em que isso predomina, pode-se dizer que há um certo negligenciamento em relação ao estímulo ao pensamento crítico e criativo em matemática. Infelizmente o sistema escolar ainda valoriza em demasia resultados de exames em vez do real aprendizado e nisso deve se considerar também o pensamento crítico e criativo em matemática. Para favorecer as produções criativas em matemática, Gontijo (2007b) sugere que os professores devem priorizar o uso de situações-problema, oferecendo atividades desafiadoras baseadas tanto no contexto vivenciado pelos alunos como em situações abstratas que demandam o uso de uma linguagem formal e de procedimentos específicos característicos da Matemática. Acrescenta, o autor, que atividades envolvendo a formulação e resolução de problemas, bem como envolvendo a redefinição de elementos matemáticos podem se converter em um valioso recurso didático para o aprendizado da Matemática e para favorecer a criatividade nesta área.

O trabalho de interpretação, de análise, de elaboração de conjecturas e de geração de várias ideias e/ou estratégias para encontrar uma solução 
apropriada para determinado problema é o que se espera que seja desenvolvido junto aos estudantes no seu percurso de formação matemática para enfrentar os desafios do século XXI. Afinal, para o pleno exercício da cidadania e para obter boas oportunidades de empregabilidade, fazem-se necessárias tais habilidades de pensamento. Saber criticar.

A parceria entre pesquisadores, professores, formadores e formuladores de políticas públicas se faz necessária para a promoção de uma educação que cumpra com aquilo que se está previsto no documento de base, bem como prepare as novas gerações para a atuação no mundo de hoje, em que o pensamento crítico e criativo é cada vez mais demandado. Um esforço deve ser feito. O pensamento crítico e criativo não pode estar presente apenas no papel, como um qualificador dos objetivos educacionais, mas deve sair dos documentos e ganhar materialidade nas práticas escolares junto aos estudantes. Uma política pública de formação continuada para professores em prol do desenvolvimento desse tipo de pensamento deve, portanto, ser elaborada e implantada. Estes termos devem ser incluídos conscientemente nos Currículos.

Por qual motivo estudamos tanta matemática, se não conseguirmos aplicá-la em nossos diferentes compromissos da vida? Este artigo se encerra com esse questionamento para que o leitor, a partir do pensamento crítico, reflita em possíveis caminhos para, a partir da criatividade, encontrar soluções plausíveis e, assim, pensarmos sobre como aprimorarmos essa capacidade de pensamento em nossas salas de aula, aprimorando a prática que adotamos na formações de nossos estudantes.

\section{Referências}

AIKEN, L. R. Ability and creativity in matheatics. Review of Educational Research. Washington, v. 43, n. 4, p. 405-432, 1973.

BRASIL, LDB. Lei 9394/96 - Lei de Diretrizes e Bases da Educação Nacional. 1996. Disponível em <http://www.planalto.gov.br/ccivil_03/leis/19394.htm>. Acesso em 10 out. 2019. 
BRASIL. Parâmetros Curriculares Nacionais: Ensino Médio, Parte III - Ciências da Natureza, Matemática e suas Tecnologias. 2000. Disponível em: $<$ http://portal.mec.gov.br/seb/arquivos/pdf/ciencian.pdf>. Acesso em 7 set. 2015.

FIRDAUS, I. K.; KAILANI, I.; BAKAR, MD. N. B.; BAKRY. Developing critical thinking skills of students in mathematics learning. Journal of Education and Learning, v. 9 (3) p. 226-236.

FONSECA, M. G.. Construção e Validação de Instrumento de Medida de Criatividade no Campo da Matemática para Estudantes Concluintes da Educação Básica. 2015. 104 f. Dissertação (Mestrado em Educação) - Faculdade de Educação, Universidade de Brasília, Brasília.

FONSECA, M. G.; GONTIJO, C. H.; ZANETTI, M. D. T. Estimulando o pensamento crítico e criativo em matemática a partir da 'Forca Numérica' e o Princípio Fundamental da Contagem. Coinspiração - Revista de Professores que Ensinam Matemática, v. 1, p. 241, 2018.

FONSECA, M. G.; GONTIJO, C. H.; ZANETTI, M. D. T; CARVALHO, A. T. Improving mathematical motivation from mathematical creativity workshops. In: 11th Proceedings of International Conference on Mathematical Creativity and Giftedness, 2019, p. 144-149.

GIL, A. C. Métodos e técnicas de pesquisa social. $6^{a}$ Ed. São Paulo: Atlas, 2008.

GONTIJO, Cleyton. Hércules. Criatividade em matemática: identificação e promoção de talentos criativos. Revista Educação, Santa Maria, v. 32, p. 481-494, $2007 \mathrm{a}$.

GONTIJO, Cleyton Hércules. Relações entre Criatividade, Criatividade em Matemática e Motivação em Matemática de Alunos do Ensino Médio. 2007. 194f. Tese (Doutorado em Psicologia) - Instituto de Psicologia, Universidade de Brasília, Brasília/DF, 2007b.

GONTIJO, Cleyton. Hércules. Técnicas de criatividade para estimular o pensamento matemático. Educação e Matemática, Lisboa, v. 135, p. 16-20, 2015.

GONTIJO, Cleyton Hércules; SILVA, Erondina Barbosa; CARVALHO, Rosália Policarpo Fagundes de. A criatividade e as situações didáticas no ensino e aprendizagem da matemática. Linhas Críticas, Brasília, v. 18, p. 29-46, 2012.

GONTIJO, Cleyton Hércules; FONSECA, Mateus Gianni; ZANETTI, Matheus Delaine Teixeira. Creative and critical thinking in mathematics: a workshop for teachers. In: 11th International Mathematical Creativity and Giftedness Conference (MCG11), 2019, Hamburg. Including the Highly Gifted and Creative Students: Current Ideas and Future Directions. Hamburg: Universität Hamburg, 2019. v. 1. p. 158-162.

HAYLOCK, D. W. The methods of fostering creativity through mathematical 
problem solving. ZDM Mathematics Education. Germany, 1997.

KANHAI, A.; SINGH, B. Some environmental and attitudinal characteristics as predictors of mathematical creativity. International Journal of Mathematical Education in Science and Technology. United States, v. 48, n. 3, p. 327-337, 2017.

LEIKIN, R.; PANTAZI, D. P. Creativity and mathematics education: The state of the art. ZDM Mathematics Education. Germany, v. 45, p. 159-166, 2013.

P21 - Partnership for 21st Century Learning. Framework for 21st Century Learning, 2016.2 Disponível em $<$ http://www.p21.org/storage/documents/docs/P21_framework_0816.pdf >. Acesso em 8 mai. 2017.

LIPMAN, Matthew. Thinking in education. UK: Cambridge University Press, 2003.

SOUZA, J. C. S. de; GONTIJO, C. H.; FONSECA, M. G. Resolução de problemas em matemática: colocando o pensamento crítico em ação. In: Regina da Silva Pina Neves; Raquel Carneiro Dörr (Orgs.). Formação de Professores de Matemática. $1^{\mathrm{a}}$ ed. Curitica- PR: Appris Editora, 2019 p. 159. 